\title{
Smoking Behavior, Cessation Techniques, and the Health Decision Model
}

STEPHEN A. ERAKER, M.D., M.P.H. * MARSHALL H. BECKER, Ph.D., M.P.H. VICTOR J. STRECHER, Ph.D., M.P.H. JOHN P. KIRSCHT, Ph.D.

Ann Arbor, Michigan
From the Veterans Administration Medical Center and the Department of Internal Medicine, Department of Health Behavior and Health Education, School of Public Heatth, University of Michigan, Ann Arbor, Michigan. Manuscript accepted June 11, 1984.

- Current address and address for reprint requests: Department of Medicine, Veterans Administration Medical Center, 111لJ, 500 Foothill Boulevard, Salt Lake City, Utah 84148.
The magnitude of the problem of smoking challenges health providers to persuade patlents of the Importance of trying to quit. Smoking behavior and cessation techniques are discussed in terms of the health decision model, a third-generation model combining health bellefs, decision analysis, and behavioral decision theory. This revlew suggests the need for physiclans to emphasize factors such as health bellefs, self-efficacy, social support, and reduction of stress in smoking cessation efforts. Patients experiencing symptoms, particularly relating to the lungs or heart, may have stronger health bellefs and are clearly more likely to qult smoking. In the absence of a clear-cut advantage for any particular smoking cessation technique, physiclans should provide advice about smoking as a regular part of every patient visit.

In 1964, the Surgeon General's report revealed that the death rate in males was 68 percent higher for smokers than for nonsmokers [1]. This finding was subsequently confirmed in the 1979 report, which also referred to smoking as the "largest preventable cause of death in America today" [2]. Smoking is clearly the primary cause of lung cancer and the most important reversible risk factor for chronic obstructive pulmonary disease and coronary artery disease [2-5]. Life expectancy for a middle-aged person who smokes two packs per day is eight years shorter than that for a nonsmoker [6]. However, persons who have quit experience an immediate and then gradual decrease in mortality rate that, by 10 to 15 years after cessation, is almost identical to the rate in lifelong nonsmokers $[2,7-10]$.

Although the overall prevalence of smoking has decreased since 1964, current estimates indicate that about one-third of all adults smoke regularly $[2,11-15]$. Annually, cigarette smoking claims close to $\mathbf{3 5 0 , 0 0 0}$ lives, accounts for more than $\mathbf{8 0}$ million days of work lost, and results in $\$ 13$ billion in medical expenses and more than $\$ 25$ billion in lost wages and productivity $[2,16]$. Furthermore, some smokingrelated problems, such as the epidemic of lung cancer in women, are clearly growing worse [17-20], and health care providers often do not identify the smoking status of their patients [21].

Although most smokers would like to quit, only 20 percent of adult Americans are former smokers [2]. Ex-smokers describe their main reasons for quitting as relating to serious health concerns $[2,22-28]$. However, reflecting an unrealistic optimism about their own susceptibility to more serious illness (e.g., lung cancer or heart disease), smokers are more concerned about symptomatic problems such as cough and dyspnea $[29,30]$. Although smoking-related symptoms often stimulate efforts to quit, fewer than 25 percent of smokers report 


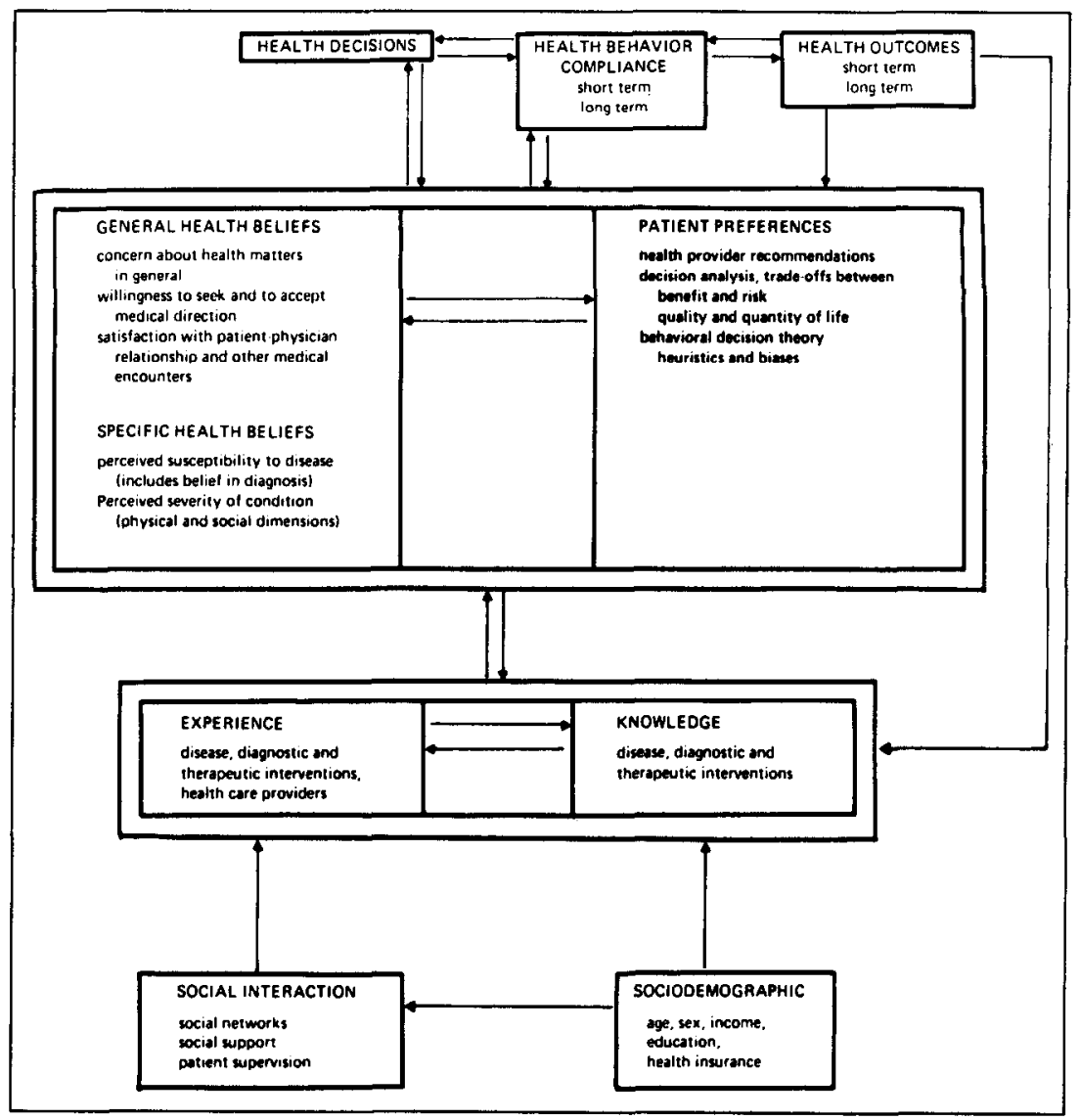

Figure 1. The health decision model, combining the health bellef model and pationt preferences, including decision analysis and behavioral decision theory. having ever been advised to stop [31]. Since 95 percent of successful ex-smokers quit on their own, rather than by formal treatment, it is clearly important for health care providers to persuade patients of the importance of trying to quit. How to accomplish this persuasion is, however, more problematic.

Comprehensive reviews of the literature on smoking cessation techniques indicate that health workers have a unique opportunity to assist patients in their efforts to stop smoking $[2,30,32-37]$. Yet, although most physicians in a recent survey agreed with the Surgeon General's recommendations regarding the importance of eliminating smoking, only 14 percent were optimistic about their ability to help patients to quit [38].

\section{SMOKING BEHAVIOR-THE HEALTH DECISION MODEL}

What can the physician interested in preventive action do to motivate patients who smoke to quit? Given the difficulty patients have in complying with physician advice, some suggestions emerge from a theoretic formulation known as the health decision model [39], presented in Figure 1. Briefly, the health decision model is a third-generation version of the health belief model
[40], which hypothesized that compliance with provider advice (e.g., to quit smoking) depends to some extent on the patient's perceptions regarding susceptibility to a disease, severity of the disease if contracted, and the benefits and barriers likely to be derived and encountered relative to undertaking a recommended action. The importance of these health beliefs in discussing compliance with medical instructions is suggested by a large body of empiric evidence $[39,40]$. The health decision model also includes recent and significant contributions of the "patient preferences" literature [41], so that a unifying model of health decisions and resultant behavior combines decision analysis, behavioral decision theory, and health beliefs. Decision analysis provides a quantitative means for patients to express their preferences about critical trade-offs between benefit and risk, at times between quantity and quality of life $[42,43]$. Behavioral decision theory extends this quantitative emphasis by identifying a number of general inferential rules that patients employ to reduce difficult mental tasks to simpler ones $[44,45]$.

Communication of information regarding health risks of smoking is influenced by numerous behavioral factors. For example, McNeil et al [46] examined pre- 
sentation of results of surgery and radiation therapy for lung cancer and found that preferences shifted depending on whether outcomes were framed in terms of probability of living or probability of dying. McNeil et al also found that "people relied more on pre-existing beliefs regarding the treatments than on the statistical data presented to them." The health decision model also recognizes the empirically documented importance of other factors affecting health decisions and behavior such as experience, knowledge, and social and demographic variables. The bi-directional arrows and feedback loops reflect findings indicating that compliance behavior can also change health beliefs [47]. The health decision model also includes concepts related to the efficacy of the prescribed regimen, motivational variables involving the person's assessment of the importance of good health, and "cues to action" that refer specifically to the patient-physician interaction. Although evidence regarding various theories of smoking behavior is at times contradictory and incomplete, the health decision model dimensions can serve as an organizing framework for our review.

\section{GENERAL AND SPECIFIC HEALTH BELIEFS}

More than 80 percent of a national sample of 12,000 agreed that smoking is detrimental to health [26]. Such beliefs about the health hazards of smoking are stronger among ex-smokers than among smokers or people who have never smoked regularly [48]. A study of patients following myocardial infarction found an overwhelming belief that smoking was of etiologic importance [49]. Public health efforts to inform people of the hazards of smoking do appear to be partially responsible for an overall reduction in the rate of cigarette smoking [11-13]. Appeals to general health beliefs have not, however, been effective in getting the large majority of individual smokers to quit [50], and one study found no association between smoking cessation and any of the sociodemographic or health belief model variables [51]. This may be because the patients were already aware that smoking is harmful. The degree to which these beliefs become personalized may also be important. For example, patients may feel that they are not personally susceptible to the hazards of smoking, a potentially alterable attitude as demonstrated by the ability to create more realistic perceptions regarding susceptibility to disease [29].

Belief in the ability to quit (i.e., self-confidence or "efficacy" expectation) has been shown to dramatically affect smoking cessation efforts. In a prospective, randomized trial [51], an experimental group was given an efficacy-reinforcing message indicating that they had strong will power, great potential to control behavior, and would completely stop smoking. After 14 months, the number of cigarettes smoked per day was reduced by 70 percent for the experimental group and by 30 percent for the control group. A strong influence on efficacy expectation is the successful accomplishment of a performance task such as decreasing smoking; however, seeing others reducing smoking or receiving suggestions are also effective influences [52]. Belief in being in control, as well as a belief in personal competence and security, have been shown to be related to a smoker's ability to quit on a long-term basis [53].

Significant associations between health beliefs related to smoking and both the desire and ability to quit smoking were recently demonstrated for patients at a Veterans Administration medical center [54]. Patients reporting high levels of both susceptibility and efficacy had the highest rates of smoking cessation and reduction. Another study of compliance with physician advice to quit smoking among patients with pulmonary disease produced some admittedly contradictory results. However, there was a significant increase in rates of smoking cessation for patients who wanted to quit, predicted they would do so, and perceived their pulmonary condition as fairly serious or expressed concern over their health status [55]. The importance of health beliefs was also supported by the finding that exsmokers see the consequences of smoking as serious and see themselves as personally susceptible to these adverse effects [56]. Moderate smokers, by contrast, do not see themselves as susceptible to health problems caused by smoking but do report smoking to be a serious health threat. It is important for the physician to discuss health beliefs to determine if patients see themselves as susceptible to the adverse effects of smoking and to provide appropriate information.

\section{PATIENT PREFERENCES AND PHYSICIAN ADVICE}

Recommendations from health care providers can have a major effect on patient preferences and subsequent behavior. Although many smokers have never been advised to stop smoking by a physician, over 70 percent of those smoking more than one pack a day said they would quit if urged to do so by a physician [57]. One well-designed study used a combination of physician advice and brief written messages with 2,138 patients of 28 London general practitioners [58]. Although the 5 percent increase over baseline in the rate of smoking cessation was small, it was statistically significant and confirmed that simple, routine advice given by physicians can effectively alter patient preferences and motivate some smokers to quit. Other, smaller studies using physician messages to get patients to quit have supported these results $[59,60]$. Physician messages are even more effective when given to patients with smoking-related illness [61]. Survivors of myocardial infarction given an antismoking message during hos- 
pitalization had a 63 percent rate of smoking cessation one to three years later, as compared with a 27 percent rate for patients given no special advice [62]. Physician messages are also more credible when given by physicians who serve as good role models because they have quit smoking themselves $[63,64]$. Smoking and nonsmoking physicians have been found to differ with regard to frequency as well as intensity of advice concerning smoking [65].

A preference for continued smoking presents a challenge to health care providers. A recently developed consultation was designed to facilitate patient decision-making and to instill the commitment to quit smoking [54]. With use of several theoretic models of decision-making $[39,41,66,67]$, practical consultation techniques were elaborated and employed with resultant significant rates of smoking reduction and cessation [54]. It is clearly important for physicians attempting to encourage smoking cessation to consider patient preferences, comprehension of benefits and risks, and decision-making processes.

\section{EXPERIENCE AND HEALTH STATUS}

Experience affects smoking behavior in a variety of ways. Stress may result in the use of nicotine as a coping mechanism to achieve either a stimulant or a sedative effect; smokers indicate that they need cigarettes under both low-arousal and high-stress conditions [68]. A number of studies have found that cigarettes help the smoker to achieve a preferred state of arousal $[69,70]$. At least in laboratory settings, smokers appear to cope better with stress when they smoke $[71,72]$, and smoking rates are higher among those experiencing life crises $[73,74]$. A recent study found anxiety to be significantly associated (gamma 0.28 to $0.38, p<0.01$ ) with expectations of being able to quit smoking, with more severe functional impairment, and with more poorly perceived health status [54]. Patients experiencing more severe health problems from continued smoking tend to comply with physician advice to quit [34]. Patients with pulmonary disease have rates of smoking cessation varying from 20 to 51 percent, with more recent studies reporting lower rates [22$24,28,61,75,76]$. Studies of smoking cessation among patients with cardiac disease also support the importance of disease as influencing compliance. Patients who have survived a myocardial infarction, particularly those who had received strong advice, are much more likely to quit smoking than are other patient groups, with 40 to 50 percent abstinence rates being common $[24,51,61,62,77,78]$. One large study found that successful smoking cessation following a myocardial infarction was positively related to both increasing age and severity of disease [78]. Patients with a more serious diagnosis also appear to have increased motivation and ability to stop $[22,75,78]$.
Addiction to nicotine and concern about withdrawal symptoms is an aspect of experience that helps to explain why smoking is so difficult to give up. Upon stopping, 90 percent of smokers experience an unpleasant withdrawal syndrome of variable duration, consisting of a drop in blood pressure, decrease in heart and metabolic rate, changes in electroencephalographic rhythms, and alterations in REM sleep patterns $[2,79]$. Other symptoms include inability to concentrate, irritability, drowsiness, tremors, fatigue, sleep disturbances, headache, nausea, alteration in bowel habits, palpitations, depression, nicotine craving, and increased appetite $[2,79]$. Symptoms tend to be worse in heavy smokers and can be decreased by chewing nicotine gum [80]. Unfortunately, the long-term toxicity of nicotine gum is not known, and the role of this gum in smoking cessation remains unclear. A recent doubleblind controlled study of nicotine chewing gum demonstrated expected blood levels of nicotine, but showed little advantage over the placebo in terms of assisting in successful smoking cessation [80]. Other pharmacologic techniques designed to decrease withdrawal symptoms - such as a series of progressively stronger filters-are of interest but have not been adequately evaluated.

\section{KNOWLEDGE}

Health care providers have a responsibility to increase patient knowledge about the health-related consequences of smoking and about techniques available to assist in the quitting process. Some patients can be motivated to stop smoking by providing a more threatening message $[60,81,82]$. It is evident, however, that any message must consider other factors, such as the strength of already-existing health beliefs. Fear messages may actually interfere with adoption of healthfacilitating behavior [59]. For example, smokers who viewed a film on lung cancer operation were less likely to undergo chest radiography than were smokers who did not see the film $[83,84]$.

Based on their knowledge, smokers have evidently decided that the benefits outweigh the risks. An awareness that the occurrence of lung cancer in a smoker is, fortunately, the exception rather than the rule influences patient knowledge. Most carcinogens, such as tobacco tar, generally take years to exert a demonstrable effect on humans, and epidemiologic models are usually needed to clarify the relationships. The difficulty in understanding and interpreting the significance of low-probability events such as lung cancer is well documented [85]. In males, smoking has been estimated to decrease life expectancy by 2,250 days [86], which is exceeded only by the decrease associated with remaining unmarried. How to evaluate and act on this information is problematic and certainly an area for considerable future research. Although patient knowl- 
edge about smoking and about related diseases and treatments influences patient decisions, its actual effect with regard to smoking cessation is unclear. This may relate to the various meanings given to "knowledge" [39], which can refer to specific information about smoking cessation techniques, to general medical information regarding the consequences of smoking, or to a reason for quitting. Thus, the type of knowledge needs to be specified before the disparate findings can be sorted out.

\section{SOCIAL INTERACTION}

The importance of social support for those attempting to quit has been demonstrated $[48,87-89]$. However, although having a nonsmoking spouse increases a patient's ability to quit, the influence of the smoking behavior of other family members, friends, or work associates is less clear [37]. The presence of socially supportive persons may help the smoker to manage stressful events, and such persons should, when possible, be included in smoking cessation efforts [87]. A recent study [54] found that the amount of encouragement a smoker expects to receive if he or she were to attempt to quit is significantly related to the desire to stop smoking (gamma $=0.28, p \leq 0.01$ ).

The health care provider can attempt to modify such interaction factors as social networks and patient supervision. This is particularly crucial to any long-term treatment plan (such as smoking cessation) that requires continuous action on the part of the patient both to quit smoking and to avoid resuming smoking. Provider-client "contracts" sometimes include an agreement by one or more family members to assist the smoker in the cessation efforts; sometimes the contracts involve "contingencies" (e.g., depositing money that is returned if nonsmoking behavior is maintained or group meetings are attended) $[88,89]$. Such contingency contracting techniques may ultimately be most useful in maintaining abstinence or in helping the lowfrequency smoker [88].

\section{SOCIODEMOGRAPHIC VARIABLES}

Although males exhibit higher overall rates of smoking, they are more likely to stop $[26,87]$ and are less likely to go back to smoking than are females $[48,90]$. Users of other drugs, such as alcohol and caffeine, have more difficulty in stopping successfuly [91]. One study found age to be a better predictor than gender of smoking abstinence [61]. Unfortunately, most sociodemographic variables are primarily descriptive and not particularly helpful in smoking cessation efforts.

\section{SMOKING CESSATION TECHNIQUES}

How can physicians assist patients experiencing difficulty in complying with advice to quit smoking? A variety of smoking cessation techniques are available and can be categorized as follows: aversive conditioning, self-control tactics, behavior modification techniques, individual counseling and educational programs, legislation, drugs, and self-help manuals. Combinations of these techniques are also available to physicians. Although evaluative findings from the literature on smoking cessation techniques are often difficult to interpret, most recent studies report a 20 to 30 percent abstinence rate at three to six months, regardless of the techniques used. Most of the studies discussed in this review, unless othewise noted, are methodologically sound, with follow-up periods of acceptable duration and with adequate sample sizes and control groups. Verification of smoking reduction or cessation, however, remains controversial.

Recent advances in biochemical assessment measures (e.g., carbon monoxide, thiocyanate, and nicotine) have been reviewed, with the conclusion that saliva thiocyanate, which exhibits the longest half-life (14 days), may be the best measure [92]. Despite statements such as "it is no longer acceptable to rely on self-reported smoking rates, no matter how they are collected"' $[92,93]$, evidence of deception with regard to smoking status is mixed. The validity of self-reports about smoking behavior varies with type of adult population studied, type of cessation therapy involved, method employed to elicit the self-reports, and social status of the investigators contacting the subjects [54]. Although some studies have noted discrepancies between biochemical indicators and self-reported status [94-97], other studies have suggested that self-reported smoking status may actually be the more accurate measure, particularly in assessing number of cigarettes smoked [98-100].

Mixed results have been obtained from a variety of aversive conditioning techniques involving: electric shocks, rapid smoking, warm stale smoke, and nicotine fading [92]. Although it initially appeared that rapid smoking could result in 100 percent cessation and 60 percent abstinence at six months, recent studies have documented rates of 20 to 30 percent abstinence $[92,101]$. Because carbon monoxide levels may reach 17 percent saturation and impair myocardial and tissue oxygenation, rapid smoking techniques are not recommended for smokers with significant heart or lung disease [102].

Focusing on the smoker's experience with internal and external (environmental) cues that trigger the urge to smoke has resulted in a variety of self-control and stimulus-control techniques. By recording circumstances in which cigarettes are smoked, the smoker eventually avoids or modifies these situations. For example, a person who usually smokes during coffee breaks may take a walk instead or drink coffee in nonsmoking areas. By shifting smokers to an external cueing mechanism (they could light a cigarette only 
when a buzzer sounded), a 73 percent reduction in smoking was attained after two months [103]. Unfortunately, although a temporary reduction in smoking is achieved, high relapse rates have been noted. Other self-control techniques have included self-rewards for specific smoking cessation behaviors [104]. A number of behavioral techniques (e.g., hypnosis, relaxation training, biofeedback, and acupuncture) have not been adequately evaluated. A carefully performed, but uncontrolled, study of hypnosis showed a 25 percent abstinence rate at six months [105]. A recently reported treatment utilizing tragus acupuncture achieved a success rate of 88 percent, with a 34 percent attrition rate and 31 percent relapse rate at two years [106].

Treatment programs that incorporate behavioral as well as cognitive decision-oriented strategies appear to be most effective in producing long-term smoking cessation [107-110]. The Multiple Risk Factor Intervention Trial (MRFIT) program is the largest nonaversive, multicomponent risk-reduction program ever subjected to careful evaluation [107]. Middle-aged men at risk for cardiovascular disease were assigned to either special intervention or usual care groups. The interventions (which varled somewhat across study sites) included maintenance visits for abstainers, repeated programs for subjects who had resumed smoking, and other behavioral, nonbehavioral, and educational strategies. After four years, the 4,103 subjects in the special intervention group had achieved a 46 percent rate of biochemically confirmed cessation as compared with a 27 percent rate for the control subjects [108]. Other combined programs have achieved impressive long-term reduction rates $[109,110]$.

Self-control procedures have sometimes been combined with aversive conditioning, which has been found to increase the effectiveness of both techniques [111-113]. Combinations of self-control and selfmonitoring techniques have been used by well-known commercial smoking cessation programs. SmokEnders is the only proprietary program to publish long-term follow-up statistics; it reports abstinence rates ranging from 70 percent at the end of the eight-week program to 27 percent after four years [37,114]. A major disadvantage of proprietary programs is the expense incurred. Whereas other behavior therapies are almost uniformly initially effective in getting a high percentage of smokers to quit, they suffer from high recidivism rates within several months [115]. By focusing primarily on smoking behavior or on the treatment process, personal health beliefs are neglected and there is a tendency to resume smoking [104]. A smoker may have learned how to quit, but has not yet internalized the decision to quit. It is increasingly evident that, to be successful in the long term, a treatment process should "foster a sense of personal responsibility for adhering to whatever decisions the client has arrived at"' [85].

Although these high-contact interventions may employ group as well as one-to-one strategies, they usually require considerable effort and time from a trained therapist. High-contact interventions also demand considerable time and expense from the smokers. Minimal-contact interventions, by contrast, usually employ brief therapist consultations and/or comprehensive self-help manuals or a variety of multicomponent approaches. Because minimal-contact interventions require fewer resources, they are potentially more cost-effective and will be more appealing to the significant number of smokers not wishing to engage in formal cessation programs. Although some trials of self-help booklets have found little or no effect on smoking cessation [116], evaluation of more recent self-help smoking cessation manuals have found an 18 percent long-term cessation rate [94]. This is similar to the cessation rate found for the American Cancer Society self-help kit under a variety of minimal-contact conditions [104]. Positive results have also been obtained with other self-help books $[117,118]$. A comparison of three self-help books under self-administered and therapist-administered conditions found that selfhelp books were more effective in getting smokers to quit or reduce smoking when combined with therapist interventions [94].

\section{COMMENTS}

Underlying the significance of smoking cessation is the issue of what physicians should do. Although a physician may believe that exhortations to quit are likely to be ignored, current evidence suggests that physicians can be effective in smoking cessation programs. A recent review concluded that "The primary physician has a major responsibility to take an active role in educating and motivating the smoker and designing a practical program for the smoker who wants to quit" [30]. Since most people who stop smoking do so by their own efforts, rather than by enroliment in formal treatment programs, it is particularly important for physicians to take advantage of their unique position of influence and attempt to convince patients of the importance of quitting. Although physicians may be in a persuasive position as authority figures, "Medical training has not traditionally emphasized the need to promote patient education and motivation" [39].

This review suggests the importance of such factors as health beliefs, self-efficacy, social support, and the absence of stress as influencing smoking behavior and as providing a focus for intervention efforts. Patients who are experiencing respiratory and cardiac problems 
may have stronger health beliefs and clearly are more likely to quit smoking. Physicians, however, need to recognize the strength of the smoking habit and how difficult it is to extinguish. It is understandable that a brief warning to an asymptomatic patient tends to be ineffective.

A comparison of the effectiveness of different types of smoking cessation programs, such as high-versus minimal-contact, is not yet available. Most programs, however, have incorporated a number of the behavioral principles discussed in this paper. An advantage of minimal-contact programs, however, is that, with rel- atively little effort, physicians could potentially reach a much larger number of smokers than can high-contact programs.

In the absence of a clear-cut advantage for any particular technique, physicians should not discourage smokers from at least trying non-harmful interventions in an attempt to quit. Smokers, however, should be cautioned against excessively costly programs and against any "magical cure" that requires no motivation or personal effort [36]. Whatever program or message is preferred by a physician, advice about smoking should be made a regular part of every patient visit.

\section{REFERENCES}

1. United States Department of Health, Education, and Welfare. Public Health Service: Smoking and health: report of the Advisory Committee to the Surgeon General of the Public Health Service. DHEW publication no. (PHS) 1103. Washington: Government Printing Office, 1964.

2. United States Department of Health, Education, and Welfare. Public Health Service: Smoking and health: a report of the Surgeon General. DHEW publication no. (PHS) 79-50066. Washington: Government Printing Office, 1979.

3. Mulcahy R, Hickey N, Graham I, McKenzie G: Factors influencing long-term prognosis in male patients surviving a first coronary attack. Br Heart J 1975; 37: 158-165.

4. Gordon T, Kannel WB, McGee D, Dawber TR: Death and coronary attacks in men after giving up cigarette smoking: a report from the Framingham study. Lancet 1974; II: 1345-1348.

5. Kuller L, Mellahn E, Townsend M, Weinberg G: Control of cigarette smoking from a medical perspective. Annu Rev Public Health 1982; 3: 153-178.

6. United States Department of Health, Education, and Welfare. Public Health Service: The health consequences of smoking - cancer. DHEW publication no. (PHS) 82-50179. Washington: Government Printing Office, 1982.

7. Wynder EL, Mabuchi K, Beattie EJ: The epidemiology of lung cancer. JAMA 1970; 213: 2221-2228.

8. Friedman GD, Petitti DB, Bawol RD, Siegelaub AB: Mortality in cigarette smokers and quitters: effect of base-line differences. N Engl J Med 1981; 304: 1407-1410.

9. Doll R, Peto R: Mortality in relation to smoking: 20 years' observations on male British doctors. Br Med J 1976; 2 . 1525-1536.

10. Rogot E: Smoking and mortality among U.S. veterans. J Chronic Dis 1974; 27: 189-203.

11. Warner KE: Clgarette smoking in the 1970's: the impact of the antismoking campaign on consumption. Science 1981; 211: 729-731.

12. Warner KE: Reactions to perceived risk: changes in the behavior of cigarette smokers. In: Covello VT, Flamm WG, Rodricks JV, Tardiff RG, eds. The analysis of actual versus perceived risks. New York: Plenum Publishing, 1983; 183-201.

13. Warner KE, Murt HA: Premature deaths avoided by the antismoking campaign. Am J Public Health 1983; 73 : 672-677.

14. Luoto J: Reducing the health consequences of smoking-a progress report. Public Health Rep 1983; 98: 34-39.

15. Marris JE: Public policy issues in the promotion of less hazardous cigarettes. In: Cori G, Bock F, eds. Banbury report
3: a safe cigarette? Cold Spring Harbor, New York: Cold Spring Harbor Laboratory, 1980; 333-338.

16. Sherin K: Smoking cessation: the physician's role. Postgrad Med 1982; 72: 99-102, 104-106.

17. United States Department of Health, Education, and Welfare, National Institute of Education: Teenage smoking: immediate and long-term patterns. Washington: Government Printing Office, 1979.

18. United States Department of Health and Human Services, Public Health Service: The health consequences of smoking for women: a report of the Surgeon General. Washington: Government Printing Office, 1980.

19. Lambert CA, Netherton DR, Finison LJ, Hyde JN, Spaight SJ: Risk factors and life style: a statewide health-interview survey. N Engl J Med 1982; 306: 1048-1051.

20. Dawley HH, Morrison J, Carrol S: A comparison of hospitalized veterans' attitudes toward smoking and smoking cessation over a four year period. Addict Behav 1980; 5: 241-245.

21. Chu FZ, Day RG: Smoking recognition by family physicians. J Fam Pract 1981; 12: 657-660.

22. Mausner J: Clgarette smoking among patients with respiratory disease. Am Rev Respir Dls 1970; 102: 704713.

23. Burns BH: Chronic chest disease, personality and success in stopping cigarette smoking, Br J Prev Soc Med 1969; 23: 23-27.

24. Rose G, Udechuku JC: Cigarette smoking by hospital patients. Br J Prev Soc Med 1971; 25: 160-161.

25. Weinblatt E, Shapiro S, Frank $\mathrm{CW}$ : Changes in personal characteristics of men, over five years, following first diagnosis of coronary heart disease. Am J Public Health 1971; 61: 831-842.

26. Centers for Disease Control: Adult use of tobacco-1975. United States Department of Health, Education, and Welfare. Public Health Service. Atlanta: Centers for Disease Control, June 1976.

27. Jones J: Cigarette abandonment: its significance. $\mathrm{Br} \mathrm{J}$ Dis Chest 1977; 71: 285-288.

28. Daughton DM, Fix AJ, Kass I, Patil KD: Smoking cessation among patients with chronic obstructive pulmonary disease (COPD). Addict Behav 1980; 5: 125-128.

29. Weinstein D: Reducing unrealistic optimism about illness susceptibility. Health Psychol 1983; 23: 11-20.

30. Rigotti NA: Techniques for the cessation of smoking. In: Gorroll AH, May LA, Mulley AC, eds. Primary care medicine. Philadelphia: JB Lippincott, 1981; 213-219.

31. Pechacek TF: Modification of smoking behavior. In: Kras- 
negor N, ed. The behavioral aspects of smoking (NIDA research monograph series no. 26, DHEW publication no. [ADM] 79-882). Washington: Government Printing Office, 1979; 127-188.

32. McAlister A: Helping people quit smoking: current progress. In: Enelow AJ, Hendrson JB, eds. Applying behavioral science to cardiovascular risk: proceedings of a conference. Seattle: American Heart Association, 1975; 147-165.

33. Wynder EL, Hoffman D: Tobacco and health: a societal challenge. N Engl J Med 1979; 300: 894-903.

34. Pederson $L$ : Compliance with physician advice to quit smoking. A review of the literature. Prev Med 1982; 11: 71-84.

35. Cummings SR: Kicking the habit: benefits and methods of quitting cigarette smoking. West J Med 1982; 137: 443-447.

36. Bigelow GE, Stitzer ML: Tobacco use and dependence. In: Psychiatric and behavioral problems. In: Zieve PV, Burton J, Barker LR, eds. Principles of ambulatory medicine. Baltimore: Williams \& Wilkins, 1982; 151-156.

37. Stepney R: Smoking behaviour: a psychology of the cigarette habit. Br J Dis Chest 1980; 74: 325-344.

38. Wechsler H, Levine, Idelson RK, Rohman M, Taylor JO: The physician's role in health promotion-a survey of primary-care practitioners. N Engl J Med 1983; 308: 97100.

39. Eraker S, Kirscht JP, Becker MH: Understanding and improving patient compliance. Ann Intern Med 1984; 100: 258-268.

40. Becker MH, ed: The health belief model and personal health behavior. Thorofare, New Jersey: Charles B. Slack, 1974.

41. Eraker SA, Politser P: How decisions are reached: physician and patient. Ann Intern Med 1982; 97: 262-268.

42. Weinstein MC, Fineberg HV, eds: Clinical decision analysis. Philadelphia: WB Saunders, 1980.

43. Hershey J: Formalization of the health belief model: measuring health belieis in compliance studies. Discussion paper 11. Philadelphia: National Health Care Management Center, University of Pennsylvania, 1979.

44. Tversky A, Kahneman D: Judgment under uncertainty: heuristics and biases. Science 1974; 185: 1124-1131.

45. Kahneman D, Slovic $P$, Tversky A: Judgment under uncertainty: heuristics and biases. New York: Cambridge University Press. 1982.

46. McNeil BJ, Pauker SG, Sox HC Jr, Tversky A: On the elicitation of preferences for alternative therapies. N Engl J Med 1982; 306: 1259-1262.

47. Taylor DW, Sackett DL, Haynes RB, Johnson AL, Gibson ES, Roberts RS: Compliance with antihypertensive drug therapy. Ann NY Acad Sci 1978; 304: 390-403.

48. Eisinger RA: Psychosocial predictors of smoking recidivism. J Health Soc Behav 1971; 12: 355-361.

49. Stewart PJ, Rosser WW: The impact of routine advice on smoking cessation from family physicians. Can Med Assoc J 1982; 126: 1051-1054.

50. Blittner M, Goldberg J: Cognitive self-control factors in reduction of smoking behavior. Behav Ther 1978; 9: 553-561.

51. Croog SN, Richards NP: Health beliefs and smoking patterns in heart patients and their wives: a longitudinal study. Am J Public Health 1977; 67: 921-930.

52. Bandura A: Self-efficacy: toward a unifying theory of behavioral change. Psychol Rev 1977; 84: 191-215.

53. Ockene J, Nuttall R, Benfari RC, Hurwitz I, Ockene IS: A psychosocial model of smoking cessation and maintenance of cessation. Prov Med 1981; 10: 623-638.

54. Strecher V: Effect of a minimal contact smoking program in a health care setting. Ph.D. dissertation, University of
Michigan, Ann Arbor, Michigan, 1983.

55. Pederson $\mathrm{LL}$, Bakerville JC, Wanklin JM: Multivariate stetistical models for predicting change in smoking behavior following physiclan advice to quit smoking. Prev Med 1982; 11: 536-549.

56. Weinberger M, Green JY, Mamlin W, Jerin MJ: Health beliets and smoking behavior. Am J Public Health 1981; 71 1253-1255.

57. American Cancer Society: A survey concerning cigarette smoking health check-ups, cancer detection tests, a summary of the findings (DHEW publication no. 79-1549). Bethesda: National Institutes of Health, 1979.

58. Russell MAH, Wilson C, Taylor C, Baker CD: Effect of general practitioners' advice against smoking. Br Med J 1979; 2 : 231-235.

59. Mausner JS, Mausner B, Rial WY: The influence of a physician on the smoking of his patients. Am J Public Health 1968; 58: 46-53.

60. Handel S: Change in smoking habits in a general practice. R Coll Gen Prac 1973; 23: 149-150.

61. Pederson LL, Williams JI, Lefcoe NM: Smoking cessation among pulmonary patients as related to type of respiratory disease and demographic variables. Can J Public Health 1980; 71: 191-194.

62. Burt A, Illingworth D, Shaw TRD, et al: Stopping smoking after myocardial infarction. Lancet 1974; l: 304-306.

63. Fletcher C, Doll RA: A survey of doctors attitudes to smoking. Br J Prev Soc Med 1969; 23: 145-53.

64. Lefcoe NM, Wonnacott TH: The prevalence of chronic respiratory disease in the male physicians of London, Ontario. Can Med Assoc J 1970; 102: 381-385.

65. Coe RM, Brehm HP: Smoking habits of physicians and preventive care practices. HSMHA Health Rep 1971; 86 217-221.

66. Janis IL, Mann L: A theoretical framework for decision counseling. In: Janis IL, ed. Counseling on personal decisions. New Haven: Yale University Press, 1982; 4772.

67. Horan JJ: Counseling for effective decision-making-a cognitive-behavioral perspective. North Scituate, Massachusetts: Duxbury Press, 1979.

68. Frith CD: Smoking behaviour and its relation to the smoker's immediate experience. Br J Soc Clin Psychol 1971; 10: 73-78.

69. Eysenck HJ: Personality and the maintenance of the smoking habit. In: Dunn WL Jr, ed. Smoking behavior: motives and incentives. Washington: V. H. Winston and Sons, 1973; 113-146.

70. Straits BC: The discontinuation of smoking: a multiple discrimination analysis. In: Zagona SV, ed. Studies and issues in smoking behavior. Tucson: University of Arizona Press, 1967: 79-81.

71. Hemistra NW: The effects of smoking on mood change. In: Dunn WL Jr, ed. Smoking behavior: motives and incentives. Washington: V. H. Winston and Sons, 1973; 197-207.

72. Nesbitt PD: Smoking, physiological arousal, and emotional response. J Pers Soc Psychol 1973; 25: 137-144.

73. Lindenthal $\mathrm{W}$, Myers JK, Pepper MP: Smoking, psychological status and stress. Soc Scl Med 1972; 6: 583-591.

74. Ben-Meir D: Fighting smoking habits in a country at war. In: Steinfeld J, Griffiths W, Ball K, Taylor RM, eds. Health consequences, education, cessation activities, and governmental action, vol. II. Proceedings of the Third World Conference on Smoking and Health (NIH publication 77-1413). Washington: Department of Health, Education, and Welfare, 1977; 937-941.

75. Dudley DL, Aickin M, Martin CJ: Cigarotte smoking in a chest clinic population-psychophysiologic variables. J Psychosom Res 1977; 21: 367-375. 
76. Raw M: Persuading people to stop smoking. Behav Res Ther 1976; 14: 97-101.

77. Rose G, Hamilton PSS: A randomized controlled trial of the effect on middle-aged men of advice to stop smoking. J Epidemiol Community Health 1978; 32: 375-381.

78. Wilhelmsson C, Vedin JA, Elmfeldt D: Smoking and myocardial infarction. Lancet 1975; l: 415-420.

79. Jarvik ME: Biological influences on cigarette smoking. In: Krasnegor $\mathrm{N}$, ed. The behavioral aspects of smoking (NIDA research monograph series no. 26, DHEW publication no. [ADM] 79-882). Washington: Government Printing Office, 1979; 7-45.

80. Russell MA, Raw M, Jarvis MJ: Clinical use of nicotine chewing-gum. Br Med J 1980; 2: 1599-1602.

81. Raw M: The treatment of cigarette dependence. Res Adv Alcohol Drug Prob 1978; 4: 441-485.

82. Rose G: Physician counselling and personal intervention. In: Steinfeld J, Griffith W, Ball KP, eds. Proceedings of the Third World Conference on Smoking and Health. Washington: Government Printing Office, 1977; 515-523.

83. Leventhal $\mathrm{H}$ : Findings and theory in the study of fear communications. Adv Exp Soc Psychol 1970: 5: 119-186.

84. Leventhal H, Cleary PD: The smoking problem: a review of the research and theory in behavioral risk modification. Psychol Bull 1980; 88: 370-405.

85. Fischhoff $B$, Lichtenstein S, Slovic P, Derby SL, Keeney RL: Acceptable risk. New York: Cambridge University Press, 1981.

86. Cohen LJ: On the psychology of prediction: whose is the fallacy? Cognition 1979; 7: 385-407.

87. Syme SL, Alcalay R: Control of cigarette smoking from a social perspective. Ann Rev Public Health 1982; 3 : 179-199.

88. Winett RA: Parameters of deposit contracts in the modification of smoking. Psychol Record 1973; 23: 49-60.

89. Elliott R, Tighe T: Breaking the cigarette habit: effects of a technique involving threatened loss of money. Psychol Record 1968: 18: 503-513.

90. West DW, Graham S, Swanson M, Wilkinson G: Five year follow-up of a smoking withdrawal clinic population. Am J Public Health 1977; 67: 536-544.

91. Matarazzo JD, Saslow G: Psychological and related characteristics of smokers and non-smokers. Psychol Bull 1960; 57: 493-513.

92. Lichtenstein $\mathrm{E}$ : The smoking problem: a behavioral perspective. J Consult Clin Psychol 1982; 50: 804-819.

93. Goeckner DJ: A multifaceted approach to smoking modification: training in alternate response strategies. Dissertation Abstracts International 1979; 40(1-B) (450 university microfilms no. 7915354).

94. Glasgow RE, Schafer L, O'Neill HK: Self-help books and amount of therapist contact in smoking cessation programs. J Consult Clin Psychol 1981; 49: 659-667.

95. Sillett RW, Wilson MB, Malcolm RE, Ball KP: Deception among smokers. Br Med J 1978; 2: 1185-1186.

96. Ohlin $\mathrm{P}$, Lundh B, Westling H: Carbon monoxide blood levels and reported cessation of smoking. Psychopharmacology 1976; 49: 263-265.

97. Petitti DB, Friedman GD, Kahn W: Accuracy of information on smoking habits provided on self-administered research questionnaires. Am J Public Health 1981: 71: 308-311.

98. Vogt TM: Questionnaires vs biochemical measures of smoking exposure (letter). Am J Public Health 1982; 72 : 93.
99. Russell MAH, Wilson C, Feyerabend C, Cole PV: Effect of nicotine chewing gum on smoking behavior and as an aid to cigarette withdrawal. Br Med J 1976; 2: 391-393.

100. Colletti G, Supnick JA, Abueg FR: Assessment of the relationship between self-reported smoking rate and ecolyzer measurement. Addict Behav 1982; 7: 183-188.

101. Lichenstein E, Harris DE, Birchler GR, Wahl JM, Schmahl DP: Comparison of rapid smoking, warm, smoky air, and attention placebo in the modification of smoking behavior. J Consult Clin Psychol 1973; 40: 92-98.

102. Miller LC, Schilling AF, Logan DL, Johnson RL: Potential hazards of rapid smoking as a technique for the modification of smoking behavior. N Engl J Med 1977; 297 : 590-592.

103. Shapiro D, Tursky B, Schwartz GE, Shnidman SR: Smoking on cue: a behavioral approach to smoking reduction. J Health Soc Behav 1971; 12: 108-113.

104. Delahunt J, Curran JP: Effectiveness of negative practice and self-control techniques in the reduction of smoking behavior. J Consult Clin Psychol 1976; 44: 1002-1007.

105. Berkowitz B, Ross-Townsend A, Kohberger R: Hypnotic treatment of smoking: the single-treatment method revisited. Am J Psychiatry 1979; 136: 83-85.

106. Choy DSJ, Lutzker L, Meltzer L: Effective treatment for smoking cessation. Am J Med 1983; 75: 1033-1036.

107. Hughes GH, Hymowitz N, Ockene JK, Simon N, Vogt TM: The multiple risk factor intervention trial (MRFIT): V. Intervention on smoking. Prev Med 1981; 10: 476-500.

108. Neaton JD, Broste S, Cohen L, Fishman EL, KJelsberg MO, Schoenberger $\mathrm{J}$ : The multiple risk factor intervention trial (MRFIT): VII. A comparison of risk factor changes between the two study groups. Prev Med 1981; 10: 519-543.

109. Powell DR, McCann BS: The effects of a multiple treatment program and maintenance procedures on smoking cessation. Prev Med 1981; 10: 94-104.

110. Hamilton SB, Bornstein PH: Broad-spectrum behavioral approach to smoking cessation: effects of social support and paraprofessional training on the maintenance of treatment effects. J Consult Clin Psychol 1979; 47: $598-600$.

111. Pechacek TF: Modification of smoking behavior. In: Smoking and health: a report of the Surgeon General (DHEW publication no. [PHS] 79-50066). Washington: Government Printing Office, 1979.

112. Conway JB: Behavioral self-control of smoking through aversive conditioning and seli-management. J Consult Clin Psychol 1977; 45: 348-357.

113. Best JA, Hakstian AR: A situation-specific model for smoking behavior. Addict Behav 1978; 3: 79-92.

114. Kanzler M, Jaffe $\mathrm{JH}$, Zeidenberg $\mathrm{P}$ : Long- and short-term effectiveness of a large-scale proprietary smoking cessation program-a 4-year follow-up of SmokEnders participants. J Clin Psychol 1976; 32: 661-674.

115. Hunt WA, Matarazzo JD: Three years later: recent developments in the experimental modification of smoking behavior. J Abnorm Psychol 1973; 81: 107-114.

116. Glasgow RE, Rosen GM: Behavioral bibliotherapy: a review of self-help behavior therapy manuals. Psychol Bull 1978; 85: 1-23.

117. Danaher BG, Lichtenstein E: Become an ex-smoker. Englewood Cliffs, New Jersey: Prentice-Hall, 1978.

118. Pomerleau OF, Pomerleau CS: Break the smoking habit: a behavioral program for giving up cigarettes. Champaign, Illinois: Research Press, 1977. 